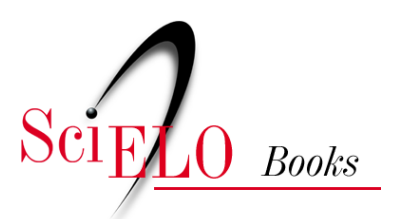

\title{
2 Tribo Barnadesieae D. Don
}

\author{
Mariana Machado Saavedra \\ Nádia Roque
}

SAAVEDRA, M.M., and ROQUE, N. Tribo Barnadesieae D. Don. In: ROQUE, N. TELES, A.M., and NAKAJIMA, J.N., comp. A família Asteraceae no Brasil: classificação e diversidade [online]. Salvador: EDUFBA, 2017, pp. 37-41. ISBN: 978-85-232-1999-4. https://doi.org/10.7476/9788523219994.0004.

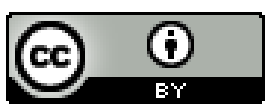

All the contents of this work, except where otherwise noted, is licensed under a Creative Commons Attribution 4.0 International license.

Todo o conteúdo deste trabalho, exceto quando houver ressalva, é publicado sob a licença Creative Commons Atribição $\underline{4.0}$.

Todo el contenido de esta obra, excepto donde se indique lo contrario, está bajo licencia de la licencia Creative Commons Reconocimento 4.0. 


\title{
TRIBO BARNADESIEAE D. DON
}

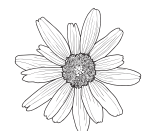 \\ Mariana Machado Saavedra \\ Nádia Roque
}

Barnadesieae é um grupo monofilético exclusivo da América do Sul, com centro de diversidade nos Andes, e que tem despertado grande interesse devido a seu posicionamento basal nas Asteraceae (BREMER, 1994, 1996).

A tribo foi descrita por David Don (1830) como uma das 9 tribos de Asteraceae, mas logo após passou a ser considerada uma subtribo (Barnadesiineae) de Mutisieae (BENTHAM, 1873), classificação esta mantida por Cabrera $(1961,1977)$. A tribo Barnadesieae foi reestabelecida após estudos de biologia molecular (JANSEN; PALMER 1987, JANSEN et al., 1991) indicarem que todos os membros das Asteraceae possuíam uma inversão no DNA do cloroplasto, com exceção da subtribo Barnadesiinae, até então subordinada à tribo Mutisieae (CABRERA, 1977). Com base nesses estudos, Bremer \& Jansen (1992) elevaram Barnadesiinae ao status de subfamília, Barnadesioideae (Benth. \& Hook. f.) K. Bremer \& R.K. Jansen, abrigando, atualmente, 83 espécies pertencentes a 9 gêneros (STUESSY; URTUBEY, 2007; SAAVEDRA, 2011).

A tribo pode ser reconhecida pelo hábito arbóreo ou arbustivo com espinhos axilares pareados ou em fascículos, raramente ervas (Schlechtendalia); lâmina foliar e brácteas involucrais com ápice mucronado ou espinescente; corola (externa, tubo e lacínias) e cipsela com tricomas "barnadesioides" (tricoma tricelular, unisseriado, com uma célula apical alongada); pápus plumoso, raramente com escamas (Schlechtendalia), barbelado ou setoso (Barnadesia). 
A tribo é composta por 3 grandes gêneros, Dasyphyllum Kunth (31 spp.), Chuquiraga Juss. (23 spp.) e Barnadesia Mutis ex L.f. (19 spp.), sendo os outros 6 representados por até 3 espécies: Arnaldoa Cabrera, com 3 espécies; Doniophyton Wedd. e Fulcaldea Poir. ex Lam., com 2 espécies cada; e Duseniella K. Schum., Huarpea Cabrera e Schlechtendalia Less., monoespecíficos. (FUNK; ROQUE, 2011; SAAVEDRA, 2011; STUESSY; URTUBEY 2007; STUESSY; URTUBEY; GRUENSTAEUDL, 2009)

\section{Descrição}

Árvores, arbustos, lianas ou ervas, monoicos ou ginodioicos; ramos eretos ou decumbentes, espinhos axilares geralmente presentes. Folhas simples, alternas, fasciculadas ou verticiladas, algumas vezes, as basais rosuladas, sésseis a pecioladas, lâmina foliar com margem inteira, glabra, glabrescente ou tomentosa, ápice frequentemente espinescente, nervação acródroma, actinódroma ou paralelódroma. Capitulescência umbeliforme, paniculiforme ou capítulos geminados ou solitários e terminais; receptáculo plano ou côncavo, epaleáceo ou com páleas esparsas ou geralmente piloso. Capítulos discoides ou radiados; invólucro campanulado, infundibuliforme, turbinado ou cilíndrico; brácteas involucrais 5-12 séries, imbricadas, desiguais, ápice apiculado até aristado. Flores 1 a numerosas, brancas, amareladas, rosa, vermelhas, lilás, flores do raio 8-13 (Barnadesia), corola pseudobilabiada $(4+1)$ ou bilabiada $(3+2)$, bissexuadas ou funcionalmente pistiladas, as do disco corola tubular ou ligulada, tubo da corola glabro, glabrescente ou seríceo; estames com apêndice do conectivo da antera inteiro ou bilobado, base da antera calcarada, caudada, base sagitada ou decorrente, filetes livres ou raramente unidos entre si (Barnadesia), inseridos próximo à base ou ápice do tubo da corola; estilete bilobado ou curtamente bífido, ramos do estilete papilosos, glabros, raro pilosos, papilas estendendo-se abaixo do ponto de bifurcação. Cipselas isomórficas, fusiformes ou heteromórficas, cilíndricas nas flores do raio e obcônicas nas flores do disco, seríceas ou tomentosas; pápus plumoso, raramente escamiforme, barbelado ou setoso, em Barnadesia, pápus das flores do raio plumoso e do disco com cerdas lineares, rígidas, acuminadas, unidas na base, eretas ou revolutas 
ao secar, unisseriadas, alvas ou estramíneas. Tricomas barnadesioides, não ramificados, 3-celulares, na corola, cipsela e pápus.

No Brasil, Barnadesieae está representada por 4 gêneros: Barnadesia, com uma espécie não endêmica do Brasil, ocorrendo no Centro-Oeste e Sudeste, nos domínios do cerrado e mata atlântica (Figura 2A); Dasyphyllum, com 15 espécies, das quais 11 são endêmicas, com distribuição extra-amazônica (Figuras 2B-C); Fulcaldea, com 1 espécie, endêmica do Brasil, na Chapada Diamantina, Bahia; e Schlechtendalia, com 1 espécie não endêmica do Brasil e distribuição nos pampas do Rio Grande do Sul (Figura 2D).

\section{Chave de identificação para os gêneros de Barnadesieae no Brasil}

1. Ervas; folhas rosuladas na base e opostas ao longo do caule, 11-nervada, nervação paralelódroma Schlechtendalia 1'. Árvores, arbustos ou lianas; folhas alternas, fasciculadas ou verticiladas, 3-7 nervadas, nervação acródroma ou actinódroma. 2

2. Capítulo com 1 flor; estilete distintamente dilatado e papiloso abaixo da bifurcação (Figura 1G) Fulcaldea 2'. Capítulo com mais de 1 flor; estilete cilíndrico e glabro abaixo da bifurcação (Figura 1H) . 3

3. Capítulos radiados; as flores radiais com corola púrpura ou rósea (Figura 2A); anteras com apêndice apical inteiro; pápus heteromórfico

Barnadesia

3'. Capítulos discoides; flores com corola alva ou creme (Figuras 2B-C); anteras com apêndice apical bilobado; pápus isomórfico Dasyphyllum

\section{Literatura recomendada}

BENTHAM, G. Compositae. In: BENTHAM, G.; HOOKER, J. D. (Ed.). Genera Plantarum. London: Reeve, 1873, v. 2, n. 1, p. 163-533. 
BREMER, K. Asteraceae: cladistics and classification. Portland: Timber Press, 1994.

BREMER, K. Major clades and grades of the Asteraceae. In: HIND, D. J. N.; BEENTJE, H. J. (Ed.). Compositae systematic: proceedings of the international Compositae conference 1994. Kew: Royal Botanic Gardens, 1996. v. 1, p. 1-7.

BREMER, K.; JANSEN, R. K. A new subfamily of the Asteraceae. Annals of the Missouri Botanical Garden, Saint Louis, v. 79, p. 414-415, 1992.

CABRERA, A. L. Revisión del género Dasyphyllum (Compositae). Revista del Museo de La Plata, Seccion Botanica, La Plata, v. 9, n. 38, p. 21-100, 1959.

CABRERA, A. L. Compuestas Argentinas: clave para la determinación de los géneros. Revista del Museo Argentino de Ciencias Naturales "Bernardino Rivadavia". Buenos Aires, v. 2, n. 5, p. 291-362, 1961.

CABRERA, A. L. Mutisieae: systematic review. In: HEYWOOD, V. H.; HARBORNE, J. B.; TURNER, B. L. (Ed.). The Biology and Chemistry of the Compositae. London: Academic Press, 1977. v. 2. p. 1039-1066.

DON, D. Descriptions of new genera and species of the Class Compositae belonging to the Floras of Peru, Mexico, and Chile. The Transactions of the Linnean Society of London, London, v. 16, n. 2, p. 169-303, 1830.

FUNK, V. A.; ROQUE, N. The monotypic Andean genus Fulcaldea (Compositae, Barnadesioideae) gains a new species from northeastern Brazil. Taxon, Utrecht, v. 60, n. 4, p. 1095-1103, 2011.

JANSEN, R. K., et al. Chloroplast DNA variation in the Asteraceae: phylogenetic and evolutionary implications. In: SOLTIS, D.; SOLTIS, P; DOYLE, J. (Ed.). Molecular Systematics of Plants. New York: Chapman \& Hall, 1991. p. 252-279.

JANSEN, R. K.; PALMER, J. D. A chloroplast DNA inversion marks an ancient evolutionary split in the sunflower family (Asteraceae). Proceedings of the National Academy of Sciences, Washington, v. 84, n. 16, p. 5818-5822, 1987. 
SAAVEDRA, M. M. Sistemática de Dasyphyllum (Asteraceae). 2011. 247 f. Tese (Doutorado em Botânica) - Instituto de Pesquisas Jardim Botânico do Rio de Janeiro, Escola Nacional de Botânica Tropical, Rio de Janeiro, 2011. STUESSY, T. F.; URTUBEY, E. Tribe Barnadesieae. In: KADEREIT, J.W.; JEFFREY, C. (Ed.). The Families and Genera of Vascular Plant: v. VIII: Flowering Plants Eudicots: Asterales. Berlin: Springer-Verlag, 2007. p. 87-90.

STUESSY, T. F.; SANG, T.; DEVORE, M. L. Phylogeny and biogeography of the subfamily Barnadesioideae with implications for early evolution of the Compositae. In: HIND, D. J. N.; BEENTJE, H. J. (Ed.). Compositae systematic: proceedings of the international Compositae conference 1994. Kew: Royal Botanic Gardens, 1996. v. 1. p. 463-490.

STUESSY, T. F.; URTUBEY, E.; GRUENSTAEUDL, M. Barnadesieae (Barnadesioideae). In: FUNK, V. A et al. Systematics, Evolution and Biogeography of Compositae. Vienna: IAPT, 2009. p. 215-228.

URTUBEY, E. Revisión del género Barnadesia (Asteraceae: Barnadesioideae, Barnadesieae). Annals of the Missouri Botanical Garden, Saint Louis, v. 86, p. 57-117, 1999. 